Article

\title{
Determinants of the Turnover Intention of Construction Professionals: A Mediation Analysis
}

\author{
Mehmet Nurettin Uğural ${ }^{1, * \mathbb{D}}$, Heyecan Giritli ${ }^{2}$ and Mariusz Urbański ${ }^{3, *}$ \\ 1 Faculty of Engineering, Istanbul Kultur University, 34158 Istanbul, Turkey \\ 2 Faculty of Architecture, Istanbul Technical University, 34467 Istanbul, Turkey; giritli@itu.edu.tr \\ 3 Faculty of Civil Engineering, Akademicka 3, Częstochowa University of Technology, \\ PL-42-200 Czestochowa, Poland \\ * Correspondence: m.ugural@iku.edu.tr (M.N.U.); murbanski@bud.pcz.pl (M.U.)
}

Received: 23 December 2019; Accepted: 21 January 2020; Published: 28 January 2020

\begin{abstract}
The voluntary turnover rate of qualified professionals is both a critical issue and a priority issue that affects organizations in different ways. The construction industry has a set of very specific and unique characteristics that demarcates it from all other sectors. This situation is related with strong precariousness and employee turnover, as well as the extensive practice of subcontracting. Furthermore, the construction sector, with its project-based production, is more vulnerable to voluntary turnover intention. Therefore, we aimed, in this study, to determine the key factors that contribute to the voluntary turnover intentions of qualified construction professionals. In this paper, the impact of individual-level value orientations on turnover intention in the construction settings, focusing on the mediating effect of external prestige and organizational identification, are investigated. Structural Equation Modeling (SEM) is employed to estimate the causal relationships between the turnover intention and other research variables. The analyses are based on questionnaire responses from 441 construction professionals living in Istanbul. The findings indicate that an individual difference in the self-construal is related to turnover intention indirectly by virtue of employees' perceptions of organizational prestige. Organizational identification also partially mediated the relationship between the self-construal and the turnover intention.
\end{abstract}

Keywords: construction project management; turnover intention; cultural values; mediation analysis; sustainability

\section{Introduction}

Understanding turnover intention and finding answers to the central questions of organizational studies, i.e., "why employees want to leave their organizations" or "why they continue to remain", [1,2] has captured the interest of a number researchers for a long time. The quest to find answers to these questions necessitates an understanding of the identifying factors that may present threats and opportunities for organizational sustainability and their sustainable development.

The term turnover is commonly referred to as movement across organizations or sectors [1]. The decision of an employee to leave an organization not only results in monetary and non-monetary costs for organizations but it is also related to the loss of the firm's competitive advantages [2].

Along with the term turnover, concepts like voluntary and involuntary movements across organizational boundaries come across. The employee initiates a voluntary movement of turnover, while involuntary turnover is initiated by the organization for various reasons, such as nonperformance. For managers, involuntary turnover can be managed and anticipated, whereas voluntary turnover tends to be unforeseen in advance [3,4]. However, the question of how to retain highly talented and valued people is generating considerable interest in improving organizational sustainability beyond 
economic sustainability. In literature, many studies [5] have focused on the turnover intention (TOI) itself, rather than on the actual turnover [6]. This is due to the difficulties of collecting data about actual turnover behavior. Depending on the currently available proof, turnover intention is a good approximation for actual turnover because it is the factor that precedes the actual TOI worker instantly and reliably [7]. Accordingly, there is a reason to argue that researchers must rely on employee TOI as a proxy construct for actual employee turnover.

It is also observed by scanning turnover literature that previous research tended to either focus on the effect of demographic factors on turnover alone [8] or, to a lesser extent, on demographic factors combined with factors as opposed to psychological and cultural variables. However, in recent years, researchers have begun to approach the subject from a psychological and mostly cultural perspective on an individual level $[9,10]$.

In most subsequent turnover research, organizational identification (OID) has been identified as a key variable in predicting turnover intention. OID has been considered as a psychological link between employees and their organization and has been proven to be relevant to TOI [10]. Among the most important antecedents of organizational identifications backgrounds, researchers have focused on perceived organizational prestige (PEP), which describes the employee's perception of how the external entities view his or her organization. Riketta's meta-analysis found that both organizational identification and organizational prestige correlate negatively with turnover [11,12].

Furthermore, evidence from organizational support literature shows that cultural values are considered an important predictor of work-related behaviors and attitudes. Despite the consensus surrounding the influence of individual cultural value orientation on TOI [13], there is little in the literature to explore whether this effect is mediated by relationship-inducing factors such as OID and PEP. Accordingly, one would expect that turnover should be studied as a process that comprises of various mediating factors, instead of studying TOIs as a single result.

The importance of voluntary employee turnover cannot be overemphasized because the loss of knowledgeable employees can be a potential threat to an organization's sustainability and their development [14]. This is especially important in a project-based industry like construction, which mostly depends on employee knowledge [15]. The construction industry has specific and different features that delineate this sector from all other sectors. This demarcation is related to a strong precariousness and labor turnover, in addition to the widespread use of subcontracting [16]. Voluntary turnover may highly be disruptive to the organization's sustainability in today's highly competitive industry. Globalization has also challenged construction organizations to achieve and maintain sustainable development [17].

Predominantly, for this reason, companies in the construction industry have to consider how to cope with the potential of losing their knowledgeable employees $[17,18]$. This is because recognizing the voluntary TOI trend is one of the main causes of insufficient efficiency, low competitiveness, and high tech loss in the industry, facing many inherent difficulties and problems, such as erratic and longer working hours $[19,20]$. Human capital is the most important cause of the successful completion of projects. Because a high rate of employee turnover is considered one of the most serious issues currently facing the construction setting, studying TOI of employees in the construction sector is particularly necessary. While turnover studies have been conducted in other industries, such as tourism [21], pharmaceutical, health, banking, [22,23] and IT [24], to our knowledge, there has been less direct research on TOI in the field of construction. [6] In addition, little is known about how individual-level constructs influence the turnover intention of construction employees, which may lead to improved organizational sustainability.

This paper focus on three individual-level constructs: (1) organizational identification, which is the cognitive and/or emotional feelings of employees about their organizational membership, (2) perceived external prestige, which refers to employees' belief of how outsiders perceive the organization, and (3) a self-construal, which is conceptualized as a "constellation of thoughts, feelings, and actions concerning one's relationship to others, and self as distinct from others" [6]. 
The objective of this study is not only to investigate the direct and indirect effects of both individualistic and collectivistic values measured at the individual level on turnover intention in construction settings but also—and more importantly—-to highlight the mediating roles of OID and PEP on this relationship. This study makes some important contributions to the literature on voluntary TOI and the consequences of cultural values in the context of the individual level. Firstly, the relationship between individual-level cultural values and TOI is investigated, which is seen as an important relationship within organizational research context. Secondly, the mediating effects of OID and PEP, which might influence the relationship between the respondent's cultural values and turnover intention, is focused on.

This paper is organized as follows: after the introduction part, the second part outlines the conceptual background, literature review, and hypotheses. Section 3 addresses the survey method, sample and questionnaire design. Section 4 then describes the statistical analysis applied, their results, and their discussion. The last part set forth the conclusions and limitations of this study.

\section{Theoretical Background and Literature Review}

\subsection{Organizational Identification, Perceived External Prestige, and Turnover Intention}

Turnover intention, external prestige, and organizational identification are key constructs in management and organizational behavior research. It is important to disentangle the causal relationships among these organization-related constructs.

Organizational identification has become one of the most significant concepts, which has been widely applied to explain employee-organization relationships. The generally accepted use of the word OID refers to the level of membership in a particular organization identified by an individual in terms of his/her membership in a particular organization [12]. Riketta [12], in his meta-analysis, has attempted to use the term as the cognitive and/or emotional feelings of employees about their organizational membership. OID can lead not only to increased job satisfaction and motivation but can also lead individuals to act in the best interests of the organization. Evidence exists that suggests sustainability management correlates with OID [25]. Slepian and Jones [26], in their global survey study, indicated that employees with high organizational identification felt significantly more concerned with sustainable development and sustainability issues.

Positive identification also reduces conflict within an organization and decreases the TOI [27]. Therefore, OID is an important necessity for job satisfaction and lower staff turnover [28].

Research evidence also confirms the significance of perceived external prestige in affecting the identification of employees towards the organization they work for [29]. In other words, perceived public credibility is seen to assume that the company holds the integrity of workers [29,30]. On logical grounds, it seems fair to suggest that the extent to which employees value the PEP of their organization directly affects their identification, resulting in low turnover [30].

Despite numerous references to the causal relationships among these organization-related constructs in academic and popular literature [31], to the best of our knowledge, few empirical studies in the project-based sector, such as the construction industry, appear to be performed. Given the significance of this sector as an employer and provider of work, the construction industry has more reasons to focus on determinants of turnover intention than most others do. In this study, both OID and PEP, being indicators of TOI, are taken in the context of the Turkish construction industry.

\subsection{The Effect of Cultural Values on Turnover Intentions}

Due to the enormous revenue costs in most organizations, understanding the impact of the orientation of individual cultural values on turnover intention is essential. Ali Taha et al. [32] underlined a need to study how culture plays a role in the causes and consequences of employee withdrawal within organizations. Recent studies have shown considering individual differences in self-constructions of employees, which may influence turnover intention [33]. In literature, mainly 
two distinct types of self-construal are proposed: independent and interdependent [34]. Independent means viewing oneself as unique and independent, whereas interdependent self-construal, on the other hand, involves seeing oneself as interrelated with others. This understanding of the self is based on the assumption that these constructs can be represented as a "bipolar dichotomy". Some authors argued that western cultures emphasize the independence and autonomy of the self, whereas eastern cultures emphasize the interdependence of the self. However, the nature of this western view of the self may not be representative of the self-construal of people from most other parts of the world [35]. Even though cross-cultural psychologists discuss the endorsement of the western type of self-construal as a universal idea, and while there exists much in the literature that suggests that the dimensions of collectivism and individualism are discrete or independent [12,36], many still maintain the bipolar dichotomy assumption [37].

Turkey is classified as a collectivistic society according to this dichotomy, and its sociocultural context is characterized by a greater emotional dependence on organizations [35,38]. Recent theorizing and empirical evidence suggest that these constructs do not necessarily form opposite poles but that all individuals and groups have access to both kinds of cognitions and will activate them depending on the situation [39]. Apart from this idea of dialectic coexistence, some also argue for complementary orientations [40,41].

Further evidence against this dichotomy assumption may lie in the findings of İmamoğlu [42], who proposed "The Balanced Integration and Differentiation (BID) Model" to show to the controversy regarding the bipolar nature of self-construal construct within the individualist-collectivist framework [42]. Her views are grounded on the assumption that "the natural order involves a balanced system resulting from the interdependent integration of differentiated components" and, as part of this natural system, human beings "have natural propensities for both differentiation and integration" [42,43].

Based on the BID model [42], this article intends to show the mediating influences of OID and PEP on the relation between individual-cultural values and turnover intention and how these interactions affect turnover intention.

\subsection{The Mediating Role of OID and PEP}

OID and PEP's mediating position has been the topic of a variety of literature studies. Most studies showed that if an organization has better prestige, it is likely to encourage individuals' identification with their organization. However, the number of researchers who attempted to test this relationship with TOI [42,43] is very scarce and they are mainly out of the construction industry.

This present research assigns turnover intention (TOI) as a dependent variable and examines the influence of OID and PEP on this intention. Specifically, as predictors and mediators, the effects of OID and PEP on TOI are investigated in this study. Based on the explanations in the Sections 2.1 and 2.2 and the Balanced Integration and Differentiation (BID) Model, the following hypotheses are addressed and Figure 1 provides a visual representation of these hypotheses.

Hypothesis 1 (H1). The individual self is positively related to TOI

Hypothesis 2 (H2). The relational self is negatively related to TOI

Hypothesis 3.1 (H3.1). PEP mediates the relationship between the individual self and TOI

Hypothesis 3.2 (H3.2). PEP mediates the relationship between the relational self and TOI

Hypothesis 4.1 (H4.1). OID mediates the relationship between the relational self and TOI

Hypothesis 4.2 (H4.2). OID mediates the relationship between the individual self and TOI 


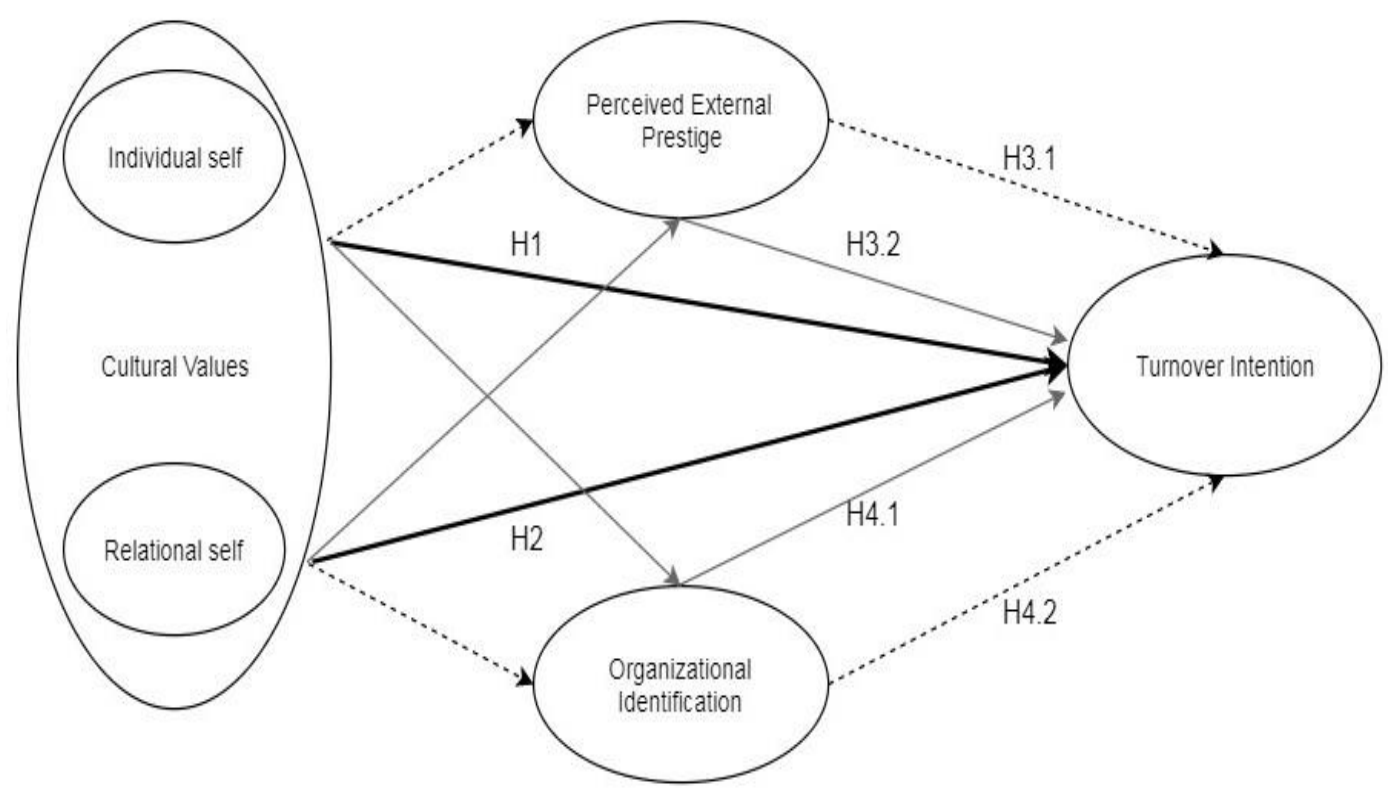

Figure 1. Visual representation of these hypotheses.

\section{Research Method}

For this study, the research method is clarified under the sections of research design, sample and procedure, measurement parts, and data analysis.

\subsection{Research Design}

This paper aims to determine the key factors that contribute to the voluntary turnover intentions of qualified construction professionals. The research approach is based on the survey. A quantitative survey is chosen as the main method of data collection. Survey questionnaires enable researchers to map the response of a large number of industry experts and generalize the findings to the population of interests. The data collected are analyzed using the SPSS v21.0, Analysis of Moment Structures (AMOS) software. Besides descriptive statistical analyses, using structural equation modeling (SEM) and path analysis are conducted.

\subsection{Sample and Procedure}

The study's target population is made up of construction experts (architects and engineers) working in the Turkish construction industry. In this study, to test the hypothesis, data are collected by using purposive or judgment sampling, which is proved effective only when there are limited numbers of people due to the qualities the participant possesses. A cross-sectional study is conducted from April to September 2015 in Istanbul. Questionnaire surveys have been issued to 960 participants registered with the Civil Engineers and Architects Chamber of Istanbul. The questionnaires are responded by 525 professionals, which represents a rate of response of $54.6 \%$. Of the 525 responses, 441 of them ( $84 \%)$ are effective responses. The sample size table, at a 5\% confidence interval, arrived at 384 employees as the sample size for a population greater than 1 million population [44] The sample size of 441 respondents (95\% confidence level and 5\% error margin) is adequate for this analysis based on the demographic and sample size of construction professionals in the Turkish construction industry. Table 1 indicates the demographic statistics of the respondents. 
Table 1. Sample profile.

\begin{tabular}{cccc}
\hline Demographic Characteristics of Respondents & Number & \% \\
\hline \multirow{2}{*}{ Gender } & Female & 168 & 38.1 \\
& Male & 273 & 61.9 \\
\hline \multirow{2}{*}{ Age } & $20-29$ & 255 & 58.0 \\
& $30-39$ & 117 & 27.0 \\
& $40-49$ & 53 & 12.0 \\
\multirow{2}{*}{ Education } & Above 50 & 16 & 3.0 \\
& Bachelor's degree & 325 & 73.7 \\
& Master's degree & 107 & 24.3 \\
& PhD & 9 & 2.0 \\
\hline \multirow{3}{*}{ Organizational Tenure } & Less than 1 year & 118 & 26.8 \\
& $1-5$ & 201 & 45.6 \\
& $6-10$ & 68 & 15.4 \\
& $11-15$ & 30 & 6.8 \\
& Above 16 & 24 & 5.4 \\
\hline \multirow{2}{*}{ Job title } & Architect & 236 & 53.6 \\
& Civil Engineer & 205 & 46.4 \\
\hline
\end{tabular}

\subsection{Measurement Instrument}

All the scales and survey items of this study that are used for testing the research hypotheses have been adapted from constructs that have been found to be valid and reliable in previous research studies. The questionnaire comprised the following four different parts and consisted of 46 items: (1) Balanced Integration-Differentiation (BID), (2) Perceived External Prestige (PEP), (3) Organizational Identification (OID), and (4) Turnover Intention (TOI). On the basis of 5-point Likert scales (5 strongly agreed, 3 neutral, 1 strongly disagreed), all the questionnaire items could be answered. Higher scores lead to higher levels of acceptance of the assessed construct being measured. The measurement scale of the Balanced Integration-Differentiation is developed by İmamoğlu [45] and has two dimensions, including a relational orientation subscale, consisting of 16 items, and an individual orientation subscale, consisting of 13 items. Cronbach's alphas in this study are 0.86 for individual orientation and 0.87 for relational orientation. In order to measure a participant's perceptions of the prestige of the company that they work for [46], a six-item PEP scale is used. The reliability of this scale is high for the respondent group (Cronbach's $=0.90$ ), the Organizational Identification (OID) is calculated by the scale introduced by Mael and Ashforth [47], and the accuracy of this six-point scale is high for the sample of respondents (Cronbach's $=0.87$ ). The last scale to measure the turnover intention (TOI) of participants is derived from a meta-analysis made by Cotton and Tuttle [48], which has five items and its scale reliability is as follows: Cronbach's $=0.89$.

\subsection{Data Analysis}

The testing of data and hypotheses is applied in SPSS v21.0. Initially, a descriptive statistical analysis and correlation analyses are performed. Then, an analysis of the confirmatory variable is used to justify the fitness of all scales used for this paper. The hypotheses about the connection between the turnover intention and the related constructs used in this study are tested using Structural Equation Modelling. Furthermore, mediation hypotheses are examined. To increase the statistical conclusion validity of the study, impotent controls, such as gender and organizational tenure, would be excluded from the analyze as suggested by Becker [49]. 


\section{Results and Analysis}

\subsection{Confirmatory Factor Analysis (CFA)}

CFA is conducted to examine the distinctive nature variables of the study and the overall fit of the hypothesized five-factor model. The following tests have been used to determine the health of the experimental models in line with the recommendations of Hair et al. [50]: a Comparative Fit Index (CFI), a Root Mean Square Error of Approximation (RMSEA), a Goodness of Fit Index (GFI), and the Chi-Square $\left(\chi^{2}\right)$ value and Degrees of Freedom (df). The CFA has showed that the hypothesized model fits well with the data $\left(\Delta \chi^{2}=1735.92, \mathrm{df}=0.97, \mathrm{RMSEA}=0.042, \mathrm{GFI}=0.853, \mathrm{CFI}=0.963\right)$.

\subsection{Mediation Analysis}

The study of mediation is taken into consideration by analyzing the interactions between the variables of the research study. This analysis is one of the most straightforward methods for recognizing the perceived relationships between dependent and independent variables by including explanatory mediating variables [51].

There are many ways of testing for mediation. Some of the most commonly employed test methods are multiple regression analyses and an analysis of moment structures (AMOS) [51,52]. In this study, path analyses are applied to check the possible mediating effects of OID and PEP on TOI, and each mediator is assessed by AMOS module Structural Equation Modeling (SEM) in SPSS.

Table 2 shows the models fit indices that are tested. In partially mediated Model 1, the individual self affects PEP, which in turn affects turnover intention. In addition, individual-self affects turnover intention directly. In partially mediated Model 2, relational-self affects organizational identification, which in turn affects TOI. In addition, relational-self affects turnover directly. In fully mediated Model 3, relational-self affects PEP, which in turn affects TOI. In fully mediated Model 4, the individual self affects OID, which in turn affects TOI.

Table 2. Fit indices for mediation models.

\begin{tabular}{ccccccccc}
\hline Model No. & Model & $\boldsymbol{\Delta} \boldsymbol{\chi}^{2}$ & $\mathbf{d f}$ & $\boldsymbol{\Delta} \boldsymbol{\chi}^{2} / \mathbf{d f}$ & RMSEA & GFI & CFI & Remark \\
\hline 1 & Partial Mediation Model & 472.151 & 4.11 & 1.943 & 0.046 & 0.914 & 0.977 & Acceptable \\
2 & Partial Mediation Model & 447.389 & 4.11 & 1.841 & 0.044 & 0.918 & 0.982 & Acceptable \\
3 & Full Mediation Model & 645.223 & 3.16 & 2.042 & 0.049 & 0.876 & 0.971 & Acceptable \\
4 & Full Mediation Model & 651.175 & 3.16 & 2.061 & 0.049 & 0.989 & 0.973 & Acceptable \\
\hline
\end{tabular}

The path from the individual self to turnover intention, as described in Table 3, is positive and important $\left(\beta=0.70, p<0.05^{*}\right)$. It ensures that the individual self orientation of respondents has a total effect—without a mediator-on turnover intention $\left(\beta=0.70, p<0.05^{*}\right)$. On the other hand, the direct path from the relational self to turnover intention is negative and significant $\left(\beta=-0.51 p<0.05^{*}\right)$. Hypothesis 1 and Hypothesis 2 are supported by these results.

Table 3. Path estimates of structural models.

\begin{tabular}{lllllcr}
\hline \multicolumn{7}{c}{ Standardized Path Coefficients Value } \\
\hline & \multicolumn{7}{c}{} & Direct effects & Partial mediation & Full mediation \\
\hline Individual self & $\rightarrow$ & Turnover Intention & & $0.73^{*}$ \\
\hline Relational self & $\rightarrow$ & Turnover Intention & & & $-0.51^{*}$ \\
\hline Individual self & $\rightarrow$ & PEP & $\rightarrow$ & TOI & $0.68^{*}$ & $0.21^{*}$ \\
\hline Individual self & $\rightarrow$ & IOD & $\rightarrow$ & TOI & $0.73^{*}$ & $0.28^{*}$ \\
\hline Relational self & $\rightarrow$ & PEP & $\rightarrow$ & TOI & $-0.52^{*}$ & $-0.06^{*}$ \\
\hline Relational self & $\rightarrow$ & IOD & $\rightarrow$ & TOI & $-0.51^{*}$ & $-0.07^{*}$ \\
\hline
\end{tabular}

Note: * significance level of 0.05 . 
Therefore, Hypotheses 3.1 and 3.2 are tested. The effects of the individual self and the relational self on turnover intention are indirect (i.e., distributed via PEP for turnover intention purposes, see Table 3.) The indirect influence of the individual self on turnover intention, while controlling the relational self is positive and significant $\left(\beta=0.21, p<0.05^{*}\right)$. By including PEP, the beta coefficient of the individual-self variable is lowered from 0.70 to 0.21 , which may indicate that the two factors had some common ground to explain the TOI. The indirect effect of the relational self on TOI through PEP is also significant $\left(\beta=-0.06, p<0.05^{*}\right.$ ), where the beta coefficient of the relational self variable is deemed to be sufficiently close to zero (from -0.51 to -0.06 ). To sum up, the above analyses showed that the effects of the individual self and the relational self on turnover intention are indirect and transmitted via PEP.

Additionally, Hypotheses 4.1 and 4.2 proposed models of indirect effects, according to which the interaction between the individual self and turnover intention (Hypothesis 4.1), as well as the relational self and turnover intention (Hypothesis 4.2), can be explained by OID. The individual self and relational self results are indirect (i.e., transmitted on TOI through OID). The indirect effect of the individual self on TOI is positive and relevant when accounting for the relational self $(\beta=0.28$, $\left.p<0.05^{*}\right)$. Nevertheless, ODI's indirect effect on turnover intention by the relational self is negative and relevant $\left(\beta=-0.07, p<0.05^{*}\right)$. The Sobel [53] test is used to test the significance of the change in the sizes of regression coefficients before and after the mediator is included in the analysis [54]. The results of the Sobel test show that both PEP and OID fully mediate the relationship between the relational self and TOI $(\mathrm{z}=4.40 ; p<0.001)$, and $(\mathrm{b})$ the relationship between the individual self and turnover intentions is partially mediated by PEP and OID $(z=6.27, p<0.001)$.

Standardized path coefficients are displayed in Figures 2 and 3 . As shown in the figures, more analyses of the strength of the indirect effects aligned with each mediator parameter separately (i.e., the control of the remaining mediator) showed that organizational identification $(0.28)$ is the strongest mediator of the individual self and turnover intention relationship, followed by perceived external prestige (0.21).

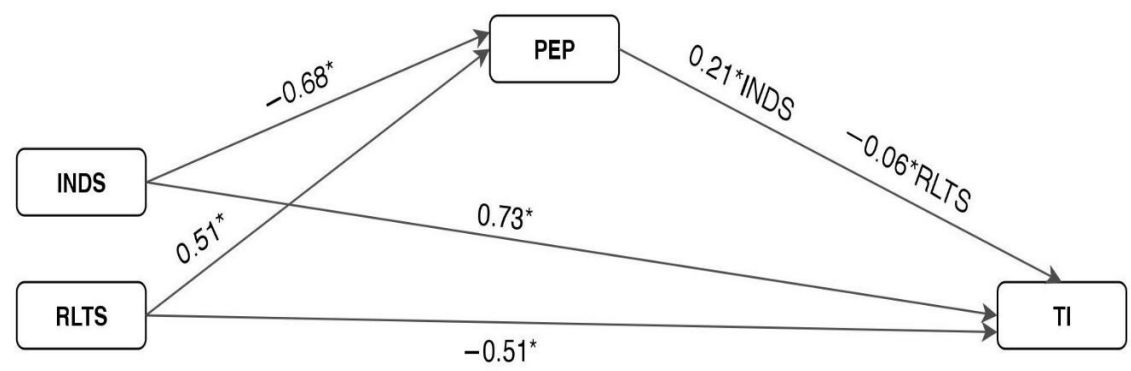

Note: *significance level of 0.05

Figure 2. Mediator effects of Perceived Organizational Prestige (PEP).

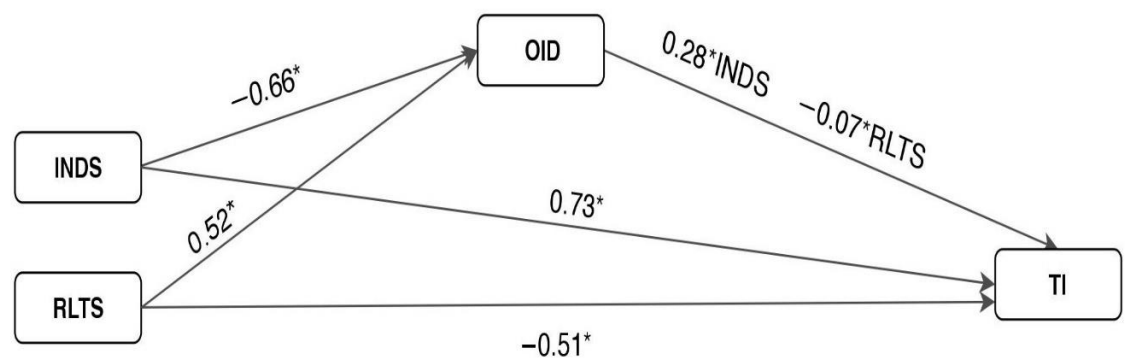

Note: *significance level of 0.05

Figure 3. Mediator effects of Organizational Identification (OID). 
Table 4 shows the summary hypothesis testing results. As the table shows, the mediation influence of OID is stronger than that of PEP. Regarding the direct relation of the self-construal to TOI, the results show that the relationship between the individual self and TOI is statistically negative. In addition, the relationship of the independent self-construal to TOI is negative, verifying the study hypothesis.

Table 4. Hypothesis results.

\begin{tabular}{clcc}
\hline Hypothesis & \multicolumn{1}{c}{ Explanation } & Analyze & Result \\
\hline H 1 & Individual self is positively related to TOI & SEM & Accepted \\
H 2 & Relational self is negatively related to TOI & SEM & Accepted \\
H 3.1 & PEP mediates the relationship among individual self and TOI & SEM & Partially Supported \\
H 3.2 & PEP mediates the relationship among relational self and TOI & SEM & Partially Supported \\
H 4.1 & OID mediates the relationship among relational self and TOI & SEM & Accepted \\
H 4.2 & OID mediates the relationship among individual self and TOI & SEM & Accepted \\
\hline
\end{tabular}

\section{Discussion and Conclusions}

Given the fact that predicting the turnover intention of talented professionals are key challenges facing firms in the construction sector, where the employee turnover rates are high, this study tried to explain why and how the two components of self-orientation, OID and PEP, differently explain the turnover intentions of construction professionals in the Turkish construction industry. In particular, we have two primary objectives in conducting this research. Our first objective is to better understand the predictors of turnover intention, which effects the organizational and economic sustainability.

The results do not support the existence of the distinct and complementary structure of the BID. In other words, relational and individuation dimensions are found to be correlated as bipolar opposites. The result of this finding is inconsistent with other research in Turkey, the United States, and Canada, all of which have used the BID scale [42]. It also raises the question of why self-construal results appear so inconsistent from study to study. Literature scanning provides a number of reasons to question the validity of self-contractual scales. Levine et al. [55], in their meta-analysis, criticize experiments that rely on student samples in previous studies on self-construal and agree that predicted cultural differences should be more evident in older adults than in college students. It is also observed that the individual self correlates and that the relational self negatively correlates with the purpose of turnover. Accordingly, relatedness and individuation are reported as endpoints of a single continuum in this study.

Levine et al. [55] point out that situational primes affect the scores of respondents on self-construction scales. Therefore, the findings discussed above might be interpreted in the context of the construction industry. There are indeed reasons to believe that construction professionals (i.e., architecture and engineering occupations) have their own common occupational culture because of their predominantly project-based work [17]. The project-based nature of the industry is identified as a major reason for turnover intentions. This raises some doubts as to the applicability of the BID to construction professionals in Turkey. Thus, some caution is called for in generalizing the findings.

The findings of this study indicate that not only are PEP and OID positively interrelated but they also have a significant negative impact on turnover intentions. The results of this study not only show that PEP and OID are positively associated with each other but they also show that PEP and OID are significantly negatively related to turnover intentions. In other words, those individuals who are high in OID are usually those who view their company as reputable, and staff with lower PEP and high OID are likely to have low TOIs [9]. Congruent with previous studies [54], this study expands the generalizability of PEP's critical role in improving the identification of organizations and their sustainability. The results also reflect the literature indicating the negative relationship between PEP and OID and the turnover intentions of employees. In view of key employees being vital to the prosperity of firms in the construction industry, these findings stress that construction industry firms need to carefully consider the influence of external prestige perceptions of key employees in their organizational identification. Our second objective is to examine whether PEP- and OID-mediated the 
relations between self-construal orientations and the turnover intention. The relationship between the relational self (RLTS) and TOI is completely mediated by PEP. PEP inclusion reduces TOI by fostering the organization's satisfaction with being a member. This finding emphasizes the importance of PEP in the provision of emotional support, which enhances the commitment of individuals to their organization. The interaction between the individual self (INDS) and the turnover intention is also found to be partially mediated by PEP.

These findings indicate that individual differences in self-orientation may be related to turnover intention indirectly through perceptions of organizational prestige. In the same vein, OID not only fully mediated the relations between the relational self and TOI but also partially mediated the relation between the individual self and TOI.

Our research adds to the body of knowledge regarding potential mediating variables in the relations between self orientations and turnover intentions in construction settings. Finally, the current study provides evidence for the widespread use of certain constructs and relationships in the cultural environment of a western environment or, more specifically, a construction context in Turkey. The results also provide clear empirical support for the argument that basic needs are universal.

\section{Limitations of the Study}

Although this research has reached its aims, the findings reported in the paper need to be taken with caution. The conventional sampling method used for this study poses some limitations for the generalizability of these findings. One limitation is that this kind of sampling tends to be biased because the chosen participants may share certain characteristics that distinguish them from the entire population, which may differ considerably. In addition, self-reports have been used to cognize turnover intention, so the results obtained may be susceptible to a specific method bias.

Author Contributions: M.N.U. worked on the original idea. M.N.U. and H.G. performed the detailed conceptualization and investigation of this research. M.N.U. coordinated the methodology and data analysis stage of this research project. M.N.U, H.G., and M.U. wrote the final draft and conducted the review, proofreading, and editing for final submission. All authors have read and agreed to the published version of the manuscript.

Funding: This research received no external funding.

Conflicts of Interest: The authors declare no conflict of interest

\section{References}

1. Zhang, M.; Fried, D.D.; Griffeth, R.W. A review of job embeddedness: Conceptual, measurement issues, and directions for future research. Hum. Resour. Manag. Rev. 2012, 22, 220-231. [CrossRef]

2. Holtom, B.C.; Mitchell, T.R.; Lee, T.W.; Eberly, M.B. 5 Turnover and Retention Research: A Glance at the Past, a Closer Review of the Present, and a Venture into the Future. Acad. Manag. Ann. 2008, 2, 231-274. [CrossRef]

3. Raišienè, A.G.; Podvezko, A.; Bilan, Y. Feasibility of stakeholder participation in organizations of common interest for agricultural policymaking. Pol. J. Manag. Stud. 2018, 18, 277-295. [CrossRef]

4. Liljegren, M.; Ekberg, K. The Associations between perceived distributive, procedural, and interactional organizational justice, self-rated health and burnout. Work 2009, 33, 43-51. [CrossRef]

5. Seibert, S.E.; Wang, G.; Courtright, S.H. Antecedents and consequences of psychological and team empowerment in organizations: A meta-analytic review. J. Appl. Psychol. 2011, 96, 981-1003. [CrossRef]

6. Jones, S.M.; Ross, A.D.; Sertyeşilış1k, B. Testing the unfolding model of voluntary turnover construction professionals. Constr. Manag. Econ. 2010, 28, 271-285. [CrossRef]

7. Perryer, C.; Leighton, C.; Firns, I.; Travaglione, A. Predicting turnover intentions: The interactive effects of organizational commitment and perceived organizational support. Manag. Res. Rev. 2010, 33, 911-923. [CrossRef]

8. Peltokorpi, V.; Allen, D.G.; Froese, F. Organizational embeddedness, turnover intentions, and voluntary turnover: The moderating effects of employee demographic characteristics and value orientations. J. Organ. Behav. 2015, 36, 292-312. [CrossRef] 
9. Singelis, T.M. The measurement of independent and interdependent self-construal's. Personal. Soc. Psychol. Bull. 1994, 20, 580-591. [CrossRef]

10. Park, C.; McQuaid, R.; Lee, J.; Kim, S.; Lee, I. The Impact of Job Retention on Continuous Growth of Engineering and Informational Technology SMEs in South Korea. Sustainability 2019, 11, 5005. [CrossRef]

11. Smeenk, S.G.A.; Eisinga, R.N.; Teelken, J.C.; Doorewaard, J.A.C.M. The effects of HRM practices and antecedents on organizational commitment among university employees. IJHRM 2006, 17, 2035-2054. [CrossRef]

12. Riketta, M. Organizational identification: A meta-analysis. J. Vocat. Behav. 2005, 66, 358-384. [CrossRef]

13. Johns, G. The psychology of lateness, absenteeism, and turnover. In Handbook of Industrial, Work and Organizational Psychology; Anderson, N., Ones, D.S., Sinangil, H.K., Viswesvaran, C., Eds.; Sage Publications: Thousand Oaks, CA, USA; London, UK, 2001; Volume 2, pp. 232-252.

14. Yang, J.T.; Wan, C.S.; Fu, Y.J. Qualitative Examination of Employee Turnover and Retention Strategies in International Tourist Hotels in Taiwan. Int. J. Hosp. Manag. 2012, 31, 837-848. [CrossRef]

15. Bilau, A.; Ajagbe, A.M.; Sholanke, A.B.; Sani, T.A. Impact of employee turnover in small and medium construction firms: A literature review. IJERT 2015, 4, 977-984.

16. Cordelia, H.S.; Florence, Y.Y.L. Strategies for reducing employee turnover and increasing retention rates of quantity surveyors. Constr. Manag. Econ. 2011, 29, 1059-1072.

17. Ozorhon, B. Analysis of construction innovation process at project level. J. Manag. Eng. 2013, 29. [CrossRef]

18. Walker, K. A Systematic Review of the Corporate Reputation Literature: Definition, Measurement, and Theory. Corp. Reput. Rev. 2010, 12, 357-387. [CrossRef]

19. Chih, Y.Y.; Kiazad, K.; Zhou, L.; Capezio, A.; Li, M.; Restubog, S.L.D. Investigating employee turnover in the construction industry: A psychological contract perspective. J. Constr. Eng. Manag. 2016, 142, 04016006. [CrossRef]

20. Du, J.J.; Zhou, J.; Liu, C.; Picken, D. Exploring turnover intention of construction managers in China. J. Constr. Res. 2006, 7, 191-205. [CrossRef]

21. Gordon, S.; Tang, C.; Day, J.; Adler, H. Supervisor support and turnover in hotels: Does subjective well-being mediate the relationship? IJCHM 2019, 31, 496-512. [CrossRef]

22. Chen, X.; Ran, L.; Zhang, Y.; Yang, J.; Yao, H.; Zhu, S.; Tan, X. Moderating role of job satisfaction on turnover intention and burnout among workers in primary care institutions: A cross-sectional study. BMC Public Health 2019, 19, 1526. [CrossRef] [PubMed]

23. Valentine, S.; Godkin, L. Banking Employees' Perceptions of Corporate Social Responsibility, Value-Fit Commitment, and Turnover Intentions: Ethics as Social Glue and Attachment. Empl. Responsib. Rights J. 2017, 29, 51-71. [CrossRef]

24. René, M.; Cynthia, K.R.; Robin, L.W. Psychological contract and turnover intention in the information technology profession. Inf. Syst. Manag. 2019, 36, 111-125.

25. Fairfield, K.D. The Role of Sense making and Organizational Identification in Employee Engagement for Sustainability. Organ. Manag. J. 2019, 16, 278-297. [CrossRef]

26. Slepian, J.L.; Jones, G.E. Gender and Corporate Sustainability: On Values, Vision, and Voice. Organ. Manag. J. 2013, 10, 215-226. [CrossRef]

27. Ashforth, B.E.; Mael, F. Social identity theory and the organization. Acad. Manag. Rev. 1989, 14, $20-39$. [CrossRef]

28. Hom, P.; Lee, T.; Shaw, J.; Hausknecht, J. One hundred years of employee turnover theory and research. J. Appl. Psychol. 2017, 102, 530-545. [CrossRef]

29. Ackers, P. Rethinking the employment relationship: A neo-pluralist critique of British industrial relations orthodoxy. IJHRM 2014, 25, 2608-2625. [CrossRef]

30. Harris, G.E.; Cameron, J.E. Multiple dimensions of organizational identification and commitment as predictors of turnover intentions and psychological well-being. Can. J. Behav. Sci. 2005, 37, 159-169. [CrossRef]

31. Karanika-Murray, M.; Duncan, N.; Pontes, H.; Griffiths, M. Organizational identification, work engagement, and job satisfaction. J. Manag. Psychol. 2015, 30, 1-17. [CrossRef]

32. Ali Taha, V.; Sirková, M.; Ferencová, M. The impact of organizational culture on creativity and innovation. Pol. J. Manag. Stud. 2016, 14, 7-17. [CrossRef]

33. Kang, C.; Huh, S.; Cho, S.; Auh, E. Turnover and retention in nonprofit employment: The Korean college graduates' experience. Nonprofit Volunt. Sect. Q. 2015, 44, 641-664. [CrossRef] 
34. Carmeli, A.; Freund, A. Linking perceived external prestige and intentions to leave the organization: The mediating role of job satisfaction and affective commitment. J. Soc. Serv. Res. 2009, 35, 236-250. [CrossRef]

35. Akgunduz, Y.; Bardakoglu, Ö. The impacts of perceived organizational prestige and organization identification on turnover intention: The mediating effect of psychological empowerment. Curr. Issues Tour. 2017, 20, 1510-1526. [CrossRef]

36. Bartels, J.; Pruyn, A.; De Jong, M.; Joustra, I. Multiple OID levels and the impact of PEP and communication climate. J. Organ. Behav. 2007, 28, 173-190. [CrossRef]

37. Deepanjana, V. Impact of self-concept on turnover intention: An empirical study. Am. Int. J. Contemp. Res. 2014, 4, 87-93.

38. Markus, H.R.; Kitayama, S. Culture and the self: Implications for cognition, emotion, and motivation. Psychol. Rev. 1991, 98, 224-253. [CrossRef]

39. Goncalo, J.; Staw, B. Individualism-collectivism and group creativity. Organ. Behav. Hum. Decis. Process. 2006, 100, 96-109. [CrossRef]

40. Triandis, H.C. Individualism and Collectivism; Westview Press: Boulder, CO, USA, 1995.

41. Hofstede, G. Culture's Consequences: International Differences in Work-Related Values; Sage: Beverly Hills, CA, USA, 2001.

42. İmamoglu, E.O.; Kuller, R.; Imamoglu, V.; Miller, M. The social psychological worlds of Swedes and Turks in and around retirement. J. Cross-Cult. Psychol. 1993, 24, 26-41. [CrossRef]

43. Kagitçibasi, C. Individualism and collectivism. In Handbook of Cross-Cultural Psychology: Vol. 3. Social Behavior and Applications (1-49); Berry, J.W., Segall, M.H., Kagitcibasi, C., Eds.; Allyn and Bacon: Boston, MA, USA, 1997.

44. Antonius, R. Interpreting Quantitative Data with SPSS; Sage Publications: London, UK, 2003.

45. İmamoğlu, E.O. Individuation and relatedness: Not opposing but distinct and complementary. Genet. Soc. Gen. Psychol. Monogr. 2003, 129, 367-402.

46. Dutton, J.E.; Dukerich, J. Keeping an eye on the mirror: Image and identity in organizational adaptation. Acad. Manag. J. 1991, 34, 517-554.

47. Mael, F.; Ashforth, B. Loyal from one day: Biodata organizational identification, and turnover among newcomers. Pers. Psychol. 1992, 48, 103-123. [CrossRef]

48. Cotton, J.; Tuttle, J. Employee turnover: A meta-analysis and review with implication for research. Acad. Manag. Rev. 1986, 11, 55-70. [CrossRef]

49. Becker, T. Potential problems in the statistical control of variables in organizational research: A qualitative analysis with recommendations. Organ. Res. Methods 2005, 8, 274-289. [CrossRef]

50. Hair, J.F.; William, C.B.; Barry, J.B.; Rolph, E.A. Multivariate Data Analysis; Prentice Hall: Upper Saddle River, NJ, USA, 2010.

51. Howell, D.C. Statistical Methods for Psychology, 7th ed.; Cengage Learning: Belmont, CA, USA, 2009.

52. Bagozzi, P.R.; Yi, Y. Specification, evaluation, and interpretation of structural equation models. Acad. Mark. Sci. 2012, 40, 8-34. [CrossRef]

53. Sobel, M.E. Asymptotic confidence intervals for indirect effects in structural equation models. In Sociological Methodology; Jossey-Bass: San Francisco, CA, USA, 1982; pp. 290-312.

54. Little, T.D.; Bovaird, J.A.; Widaman, K.F. On the merits of orthogonalizing powered and product terms: Implications for modeling interactions among latent variables. Struct. Equ. Model. 2006, 13, 497-519. [CrossRef]

55. Levine, T.R.; Bresnahan, M.J.; Park, H.S.; Lapinski, M.K.; Wittenbaum, G.M.; Shearman, S.M.; Lee, S.Y.; Chung, D.; Ohashi, R. Self-construal scales lack validity. Hum. Commun. Res. 2003, 29, 210-252. [CrossRef]

(C) 2020 by the authors. Licensee MDPI, Basel, Switzerland. This article is an open access article distributed under the terms and conditions of the Creative Commons Attribution (CC BY) license (http://creativecommons.org/licenses/by/4.0/). 